\title{
Charges for Charges: Home Sales under the Care Act 2014 \\ Brian Sloan*
}

\section{Introduction}

Healthcare is broadly provided free at the point of delivery in England by the National Health Service. ${ }^{1}$ By contrast, social care (which supports people with physical, cognitive or age-related conditions in carrying out personal care or domestic routines) is subject to a means test that can include the care recipient's home. ${ }^{2}$ One principle embodied in the Care Act 2014 is nevertheless the frequent undesirability of a social care recipient being forced to sell her own home during her lifetime to fund her care. ${ }^{3}$ It therefore seeks to increase the availability of deferred payment agreements (DPAs), enabling a local authority to make a secured loan to the care recipient in order to fund the care. ${ }^{4}$ It seems that there will be "situations where the local authority is contracting with [a] care home on the person's behalf (and is deferring charging the person)'

\footnotetext{
" College Lecturer \& Fellow in Law, Robinson College, Cambridge. This chapter arises out of the author's project on 'Adult Social Care and Property Rights', begun during an Early Career Fellowship at the Centre for Research in the Arts, Social Sciences and Humanities (CRASSH), Cambridge, in 2015 and supported by a Cambridge Humanities Research Grant. The author is grateful for the comments of attendees at a Centre for Public Law seminar in Cambridge in February 2016 and the MSPL conference, and those of the anonymous referee, on earlier drafts. The usual disclaimer applies.

${ }^{1}$ National Health Service Act 2006, s 1(4).

${ }^{2}$ See generally Commission on Funding of Care and Support, Fairer Care Funding (Commission on Funding of Care and Support, 2011).

${ }^{3}$ See, eg, N Hopkins and E Laurie, 'Social Citizenship, Housing Wealth and the Cost of Social Care: Is the Care Act 2014 “Fair”?' (2015) 78 Modern Law Review 112, 134-38.

${ }^{4}$ Care Act 2014, s 34-36.
} 
and also "situations where the person is contracting with [a] care home themselves and the local authority is effectively "loaning" the person money to pay their care home costs'.

Even if this system is beneficial to care recipients themselves (albeit in an emotional rather than necessarily material sense), it could have profound implications for people (to be termed '(former) co-residents') who wish to remain in the home of a now-deceased recipient. This is particularly true given that the secured loan facilitated by a DPA is due for repayment just 90 days after a recipient's death, ${ }^{6}$ and that former co-residents might be vulnerable former providers of informal care. ${ }^{7}$ As Hopkins and Laurie put it, the system seeks to preserve 'the paradigm of housing as home' during a care recipient's life, but not to further 'the paradigm of housing as an inheritance'. ${ }^{8}$ Former co-residents are affected by a debt owed to the state by a third party and borne out of necessitous circumstances, a debt that would not have arisen had the third party's needs been sufficiently different to be covered by the NHS. The fact that the co-resident has been able to live in the property for the remainder of the care recipient's life and the claim that 'many people choose to use a deferred payment agreement as a "bridging loan" to give them time and flexibility to sell their home when they choose to do so' must nevertheless be taken into account, ${ }^{9}$ as must the negative consequences if the social care system were unable to provide for those who require care but lack the means to pay for it altogether.

This chapter aims to evaluate the relationship between former co-residents and home sales forced by local authorities, comparing a former co-resident's position with that of others whose homes are the subject of attempted forced sale by creditors in other contexts, by examining law, guidance and codes of practice. The fundamental question is whether the system of DPAs

\footnotetext{
5 Local Government Association, 'Deferred Payment Agreements' (7 January 2016), available at www.local.gov.uk/care-support-reform/-/journal_content/56/10180/6522542/ARTICLE（accessed on 29 November 2016.

${ }^{6}$ Care and Support (Deferred Payment) Regulations, SI 2014/2671, r 7.

${ }^{7}$ See, eg, $R$ v Somerset County Council, ex p Harcombe (1997) 96 LGR 444 (QB); see generally B Sloan, Informal Carers and Private Law (Oxford, Hart Publishing, 2013). For discussion of the possible difficulties with dispositions to such carers, see eg B Sloan, 'Reversing Testamentary Dispositions in Favour of Informal Carers' in B Häcker and C Mitchell (eds), Current Issues in Succession Law (Oxford, Hart Publishing, 2016).

${ }^{8}$ Hopkins and Laurie (n 3) 135.

${ }^{9}$ Department of Health, 'Care and Support Statutory Guidance' (2016), available at www.gov.uk/guidance/careand-support-statutory-guidance [9.6] (accessed on 16 November 2016).
} 
and related matters governed by the Care Act adequately balances the perceived societal interest in ensuring that those with means contribute towards their care costs and the individual interests of former co-residents in remaining in their own homes both before and after the death of a social care recipient. The chapter begins by considering the relevance of a care recipient's home to the initial assessment of liability to pay for social care. Section III then analyses the law concerning the creation of charges on the home (including via DPAs) both before and under the Care Act, before the last substantive section considers the actual enforcement of debts and sale of homes in the context of social care. The chapter argues that while there are some points of concern, former co-residents are generally in a justifiably stronger position than coresidents of private creditors, and that most prejudice is caused by the underlying policy of means testing for social care.

\section{The Home and Liability for Care Fees}

\section{A. An Outline of the Social Care Funding System}

Before the details of deferred payment agreements and home sales are considered, the system of funding social care and financial assessment must be outlined. Under the social care system pre-dating the full implementation of the Care Act in England, '[v]ery broadly, ... people with assets over $£ 23,250$ receive no financial state support and need to fund their own care' and '[t]he level and type of state support for people with assets below this threshold depends on their needs and income'. ${ }^{10}$ A care recipient's liability to pay is assessed by a local authority (separately to a needs assessment ${ }^{11}$ using an extremely complex set of regulations to determine the existence of relevant capital and income. ${ }^{12}$ There is currently a general obligation to charge when the relevant capital limits are exceeded only where care is to be provided in a care home, ${ }^{13}$ as distinct from when it is to be provided in the care recipient's own home. The Care Act's

\footnotetext{
${ }^{10}$ Commission on Funding of Care and Support (n 2) 11.

${ }^{11}$ Care Act 2014, ss 9-13.

${ }^{12}$ Care and Support (Charging and Assessment of Resources) Regulations, SI 2014/2672, made under Care Act 2014, ss 14 and 17, inter alia.

${ }^{13}$ Care and Support (Charging and Assessment of Resources) Regulations, r 12(2).
} 
Impact Assessment, however, suggests that this obligation will be removed and replaced with a discretion to charge in both contexts when the Act is fully brought into force. ${ }^{14}$ Statutory guidance also plays a key role within the social care system. ${ }^{15}$

Inter alia, the Care Act (much of which came into force in April 2015) sought to rationalise the provision of social care ${ }^{16}$ and to limit the amount that any one person can be expected to contribute towards her lifetime care costs. ${ }^{17}$ That said, the implementation of the cap on eligible lifetime care costs (expected to be $£ 72,000$ in the first instance where a person's care needs had developed after the age of 25) has been delayed from April $2016^{18}$ to April 2020. ${ }^{19}$ In addition, while the threshold below which means-tested help is provided was to increase to from $£ 23,250$ to $£ 27,000$ where the person's home was not included in the financial assessment and $£ 118,000$ where it was included, ${ }^{20}$ there were a number of significant limitations on the cap's effect even before the delay was announced, ${ }^{21}$ and many individuals will be expected to contribute a significant sum towards care costs even if the Act's funding provisions are fully commenced.

\section{B. The Significance of 'Disregards' in Protecting Co-Residents}

\footnotetext{
${ }^{14}$ Department of Health, Impact Assessment: The Care Act 2014 (Department of Health, 2014) [1.116].

${ }^{15}$ Department of Health, 'Care and Support Statutory Guidance' (n 9). For analysis of the guidance's legal effect, see B Sloan, 'Trusts and Anti-Avoidance under the Care Act 2014' [2015] The Conveyancer and Property Lawyer $489,499$.

${ }^{16}$ See, eg, Care Act 2014, s 13.

${ }^{17}$ ibid s 15 .

${ }^{18}$ Department of Health, The Care Act 2014: Consultation on Draft Regulations and Guidance to Implement the Cap on Care Costs and Policy Proposals for a New Appeals System for Care and Support (Department of Health, 2015).

${ }^{19}$ Department of Health, 'Letter from Rt Hon Alistair Burt MP: Delay in the Implementation of the Cap on Care Costs' (17 July 2015), available at www.gov.uk/government/publications/delay-in-the-implementation-of-thecap-on-care-costs (accessed on 29 November 2016).

${ }^{20}$ Department of Health, The Care Act 2014: Consultation on Draft Regulations (n 18) [9.7].

${ }^{21}$ See, eg, B Sloan, ‘Adult Social Care and Property Rights' (2016) 36 Oxford Journal of Legal Studies 449.
} 
A fundamentally important means of protecting the care recipient's home (and a co-resident's ability to continue living in it) at the financial assessment stage must be appreciated. This is the fact that a home can in many cases be excluded from a local authority's assessment of the care recipient's capital in the first place. If an adult care recipient is to receive non-residential care in her own home, assessment of her capital must exclude her main or only home. ${ }^{22}$ Even if the care recipient is to receive residential care in a care home, the very presence of some of the co-residents with whom this chapter is concerned can prevent a home from being included in the local authority's assessment from the outset, meaning that the care recipient will be assessed as though she did not have an interest in it for these purposes. There is a mandatory 'disregard' not only if the care recipient is in a care home temporarily and intends to return to the main home or is taking reasonable steps to dispose of it, but also if the main home is occupied by a non-estranged partner, a single parent who is an estranged partner, or a relative aged 60 or over or under 18 , or who is incapacitated. ${ }^{23} \mathrm{~A}$ 'relative' for these purposes is defined very broadly within the statutory guidance. ${ }^{24}$ It is extremely noteworthy that these provisions are based on the occupation of relevant individuals alone, who need not have any entitlement in the home at all.

There is a discretion to disregard the home in other circumstances, ${ }^{25}$ such as where there is a co-resident who is not a qualifying relative for the purposes of the mandatory disregard. Forbes $\mathrm{J}$ held that when considering whether to exercise the equivalent discretion in the pre-Care Act regulations, ${ }^{26}$ it was necessary to 'maintain an appropriate balance between the exercise of that discretion and the need to observe the important underlying principle of the legislative scheme',

\footnotetext{
${ }^{22}$ Care and Support (Charging and Assessment of Resources) Regulations, sch 2, para 4; Department of Health, 'Care and Support Statutory Guidance' (n 9) [8.43].

${ }^{23}$ Care and Support (Charging and Assessment of Resources) Regulations, sch 2, paras 1-8; Department of Health, 'Care and Support Statutory Guidance' (n 9) Annex B, [34].

${ }^{24}$ Department of Health, 'Care and Support Statutory Guidance' (n 9) Annex B, [35].

${ }^{25}$ Care and Support (Charging and Assessment of Resources) Regulations, sch 2, para 4(2); Department of Health, 'Care and Support Statutory Guidance' (n 9) Annex B, [42]-[44].

${ }^{26}$ National Assistance (Assessment of Resources) Regulations 1992 SI 1992/2977.
} 
namely 'to ensure that [care home] residents with assets are not maintained at public expense'. ${ }^{27}$

Cases where a relative moves into the property only after the adult has become resident in a care home are included in the scope of the discretionary disregard. When the Court of Appeal considered the pre-Act disregard relating to occupation of a care recipient's home by family members in Walford $v$ Worcestershire County Council, Underhill LJ noted that the new regulations 'deal more explicitly with the issue' than the old ones. ${ }^{28}$ There is also a 12 -week disregard of the value of the home when the adult first enters a care home or another disregard ends unexpectedly because a qualifying relative dies or goes into a care home himself. ${ }^{29}$ There is a discretion to disregard in relation to other unexpected changes of circumstance. ${ }^{30}$

As discussed in Section III, a deferred payment agreement is unlikely to be offered where a care recipient has been assessed as liable to contribute towards care costs and has relevant property other than the main home. This, in turn, means that where a home is disregarded, it is unlikely to be subject to a DPA, a state of affairs likely to benefit co-residents. There may nevertheless be circumstances where arrears of care fees have accumulated (perhaps at the time of death) and the home is sold in order to meet the debts of the estate without reference to a DPA or even where a home was disregarded in the initial financial assessment. The enforcement of debts is considered in Section IV of this chapter.

Even if a home is not formally disregarded, the value of a non-care recipient's share of it in principle should not be included in the financial assessment, ${ }^{31}$ and it may be difficult for a local authority to justify taking even the care recipient's share in the home into account where someone else has an interest in it given that " $[\mathrm{t}]$ he [relevant] current market value will be the price a willing buyer would pay to a willing seller' ${ }^{32}$ Where the property in question is land, the regulations quite properly disapply the general principle that where the care recipient and

\footnotetext{
${ }^{27} R v$ Somerset County Council, ex p Harcombe (n 7) 456.

${ }^{28}$ Walford v Worcestershire County Council [2015] EWCA Civ 22, [2015] PTSR 880 [17].

${ }^{29}$ Care and Support (Charging and Assessment of Resources) Regulations 2014, sch 2, para 4(3).

${ }^{30}$ Department of Health, 'Care and Support Statutory Guidance’ (n 9) Annex B, [45]-[46].

31 ibid [8.8].

${ }^{32}$ ibid Annex B, [15].
} 
others are beneficially entitled to capital 'each person is to be treated as if each of them were entitled in possession to an equal share of the whole beneficial interest' ${ }^{33}$ If the care recipient deliberately alienates part of the beneficial interest in order to avoid liability for care fees, however, this is likely to trigger the Care Act's anti-avoidance provisions, which allow a local authority to treat her as though she still owned it (subject to the market value issue just considered) or to pursue the disponee for a relevant amount. ${ }^{34}$ Moreover, it will be seen in Section III that where the presence of a co-resident has not prevented the offering of, and entry into, a DPA, the notion of priority for the purposes of the DPA regulations might prejudice the protection apparently given to a co-resident's share.

This sub-section has demonstrated that there are a number of circumstances in which the sale of a home forced by a local authority will not in principle become a realistic prospect because of the existence of a co-resident. These circumstances are notably peculiar to the liability to pay for social care, and are advantageous to such co-residents as compared to (perhaps more familiar) situations involving private-sector creditors. There will nevertheless be cases where a home sale at the behest of a local authority would be possible and could prejudice the interests of a former co-resident, and the remainder of this chapter deals with these. The next section addresses the creation of charges on the home, a highly significant means of facilitating such sales.

\section{Social Care and the Creation of Charges on the Home}

\section{A. Deferred Payment Agreements pre-2015 and Charges under the 1983 Act}

It has been seen that, aside from the cap on care costs, a major area of funding reform within the Care Act relates to the widespread offering of deferred payment agreements, which allow for the payment of social care costs to be deferred (effectively via a secured loan) until a certain

\footnotetext{
${ }^{33}$ Care and Support (Deferred Payment) Regulations, SI 2014/2671, r 24.

${ }^{34}$ Care Act 2014, s 70; see generally Sloan, 'Trusts and Anti-Avoidance under the Care Act 2014' (n 15).
} 
point, such as the death of the care recipient or the (potentially voluntary) sale of her home. ${ }^{35}$ Despite their opposition to the cap, Hopkins and Laurie support the new principle of 'universal deferred payment'. ${ }^{36}$ As discussed in more detail in the next sub-section, as well as retaining a discretion to offer a DPA, local authorities are prima facie obliged to do so to an adult whose needs are to be met in a care home, who has no more than $£ 23,250$ in assets other than any interest in the home and the home is not disregarded. ${ }^{37}$ This is significant because of the concern that people could be forced to sell their homes during their own lifetimes in order to pay for their care, although some have questioned the idea that people have been 'forced' to sell their homes in a real sense, and pointed to the advantages of doing so in certain situations. ${ }^{38}$ The postponement of sale would bring short-term advantages to a co-resident even if it did not protect their interests in the longer term.

In any case, Spencer-Lane notes several weaknesses in the pre-2015 DPA scheme, ${ }^{39}$ which was contained in the Health and Social Care Act 2001. ${ }^{40}$ There was no obligation on local authorities to offer DPAs, and the Impact Assessment for the Care Act reported a 'wide variation in both the number of deferred payment agreements offered in local authorities and in the eligibility conditions attached to local schemes', such that only around 4,000 people entered them each year. ${ }^{41}$ In addition, local authorities were not able to charge interest until after the relevant person had died.

Moreover, some local authorities apparently preferred to use their general debt recovery powers under the Health and Social Services and Social Security Adjudications Act 1983 because those

\footnotetext{
35 The DPA prima facie falls due for repayment 90 days after the person's death or on disposal of property on which the local authority has a charge: Department of Health, 'Care and Support Statutory Guidance' (n 9) [9.104]; Care and Support (Deferred Payment) Regulations 2014, r 7.

${ }^{36}$ Hopkins and Laurie (n 3) 137.

${ }^{37}$ Care and Support (Deferred Payment) Regulations 2014, r 2.

${ }^{38}$ T Spencer-Lane, Care Act Manual, 2nd edn (London, Sweet \& Maxwell, 2015) [1-373].

${ }^{39}$ ibid [1-371].

${ }^{40}$ Health and Social Care Act 2001, s 55.

${ }^{41}$ Department of Health, Impact Assessment: The Care Act 2014 (n 14) [8.3].
} 
allowed a charge to be placed on the home ${ }^{42}$ but did not require consent. ${ }^{43}$ The Court of Appeal in Walford was told that

in a case where a resident owns property which is not the subject of a disregard but has no significant income it is standard practice for authorities to take such a charge, though they may choose not to seek to enforce it forthwith. ${ }^{44}$

This ability to create a charge unilaterally was detrimental to both care recipients and coresidents, albeit that, as the Land Registry put it, '[w] here the [care home] resident is a joint owner, the charge affects only his or her beneficial interest, not the registered legal estate', and 'section 22(5) provides that the joint tenancy is not severed, but the charge will be for an amount not exceeding the value of the interest which the resident would enjoy if the tenancy were severed'. ${ }^{45}$ Section 69 of the 2014 Act, which addresses debt recovery, does not contain an express power to create such a charge, which is beneficial to both care recipients and coresidents, albeit that matters may be different to the situation described by the Land Registry where a charge has been imposed by consent under a DPA. The Act does leave open the possibility of 'alternative financial arrangements' to DPAs, but the section providing for them is not in force at the time of writing. ${ }^{46}$ The details of the new DPA scheme, and its implications for co-residents, are considered in the next sub-section of this chapter.

\section{B. Deferred Payment Agreements under the Care Act 2014}

The government reported that '[ $t$ ]he majority of respondents' to its consultation exercise were 'highly supportive of the overall intention to extend the deferred payments scheme' under the

\footnotetext{
${ }^{42}$ Health and Social Services and Social Security Adjudications Act 1983, s 22.

${ }^{43}$ Spencer-Lane (n 38) [1-371] (apparently containing a typographical error).

${ }^{44}$ Walford $v$ Worcestershire County Council (n 28) [22] (Underhill LJ).

${ }^{45}$ Land Registry, 'Practice Guide 19: Notices, Restrictions and the Protection of Third Party Interests in the Register' (2016), available at www.gov.uk/government/publications/notices-restrictions-and-the-protection-ofthird-party-interests-in-the-register/practice-guide-19-notices-restrictions-and-the-protection-of-third-partyinterests-in-the-register (accessed on 29 November 2016) [6.22].

${ }^{46}$ Care Act 2014, s 36.
} 
2014 Act. ${ }^{47}$ The new DPA scheme is designed to be cost-neutral, such that interest rates and administration charges can be levied. There is a national maximum interest rate specified in a circular, and the guidance suggests a given local authority must use the same rate for all of its DPAs. $^{48}$

On particular issues, 'some [consultation] respondents suggested that the guidance needed to provide further clarity around how to manage issues associated with lack of mental capacity' ${ }^{49}$ There were concerns about 'people entering into deferred payment agreements ... inappropriately when they lacked capacity, and what might happen if people lost capacity whilst in DPAs' ${ }^{50}$ It was also noted that

A number of consultees also pointed out that, given that DPAs may be relatively brief in length, people should be provided with statements of the amount deferred at more frequent intervals, and should be able to request statements as and when they were needed ${ }^{51}$

and '[s]ome respondents also suggested that the guidance should be clearer that local authorities should signpost people to independent financial advice (including regulated financial advice but only where appropriate ${ }^{[52]}$ when considering taking out a DPA'. ${ }^{53}$ The guidance was amended to reflect all of these concerns. The guidelines on the equity limit (explained below) have also been simplified. While 'the majority of respondents were supportive of the suggestion to incentivise rental by allowing people to retain a proportion of any income they generated from letting their property', ${ }^{54}$ this will not always be feasible where there is a former co-resident.

\footnotetext{
${ }^{47}$ Department of Health, Response to the Consultation on Draft Regulations and Guidance for Implementation of Part 1 of the Care Act 2014 (Cm 895536, 2014) 27.

${ }^{48}$ Department of Health, 'Care and Support Statutory Guidance' (n 9) [9.66]-[9.67].

${ }^{49}$ Department of Health, Response to the Consultation on Draft Regulations and Guidance (n 47) 27.

${ }^{50}$ ibid 27.

${ }^{51}$ Department of Health, Response to the Consultation on Draft Regulations and Guidance (n 47) 28.

${ }^{52}$ See, eg, Spencer-Lane (n 38) [1-047]-[1-048].

${ }^{53}$ Department of Health, Response to the Consultation on Draft Regulations and Guidance (n 47) 28.

54 ibid 28.
} 
There are nevertheless still concerns that the de facto asset threshold for the mandatory offering of a DPA (effectively $£ 23,250$ in the first instance, as described above) and the apparent likelihood that only people with slightly more than that would be offered one on a discretionary basis effectively prevent the scheme from being universal, although the asset threshold could change. The Impact Assessment asserts that 'self-funders would not be eligible for a deferred payment if they had more than $£ 23,500$ [sic] in savings', 55 although it is presumably referring to eligibility for a mandatory DPA. While it justifies this situation on the basis that '[a]nyone above this threshold could typically afford to pay for a year of residential care out of their savings, without having to draw on their housing wealth', ${ }^{56}$ it is a significant limitation that might risk greater use of unsuitable equity release products, ${ }^{57}$ albeit that (as discussed in Section II) it could facilitate the protection of the home for the benefit of a co-resident inter alia.

The Impact Assessment also makes clear that 'local authorities will be required to seek adequate security for a deferred payment agreement ${ }^{58}$ which is borne out by the Care and Support (Deferred Payment) Regulations, ${ }^{59}$ and such an authority can refuse to enter an agreement with someone who meets the general mandatory criteria if it is unable to obtain a first charge by way of legal mortgage over the person's property. ${ }^{60}$ It also has a discretion to accept another form of security in line with a policy. ${ }^{61}$ With regard to the sort of charge considered acceptable 'the majority [of consultation respondents] were opposed to local authorities being required to accept any legal charge, and in favour of authorities only being

\footnotetext{
${ }^{55}$ Department of Health, Impact Assessment: The Care Act 2014 (n 14) [8.11].

${ }^{56}$ ibid [8.11].

${ }^{57}$ See generally L Fox O’Mahony, Home Equity and Older Owners: Between Risk and Regulation (Oxford, Hart Publishing, 2012); cf Hopkins and Laurie (n 3) 137-138.

${ }^{58}$ Department of Health, Impact Assessment: The Care Act 2014 (n 14) [8.46]; cf Hopkins and Laurie (n 3 ) 134.

${ }^{59}$ Care and Support (Deferred Payment) Regulations 2014, r 4(1).

${ }^{60}$ Care and Support (Deferred Payment) Regulations 2014, r 4; Department of Health, 'Care and Support Statutory Guidance' (n 9) [9.12]; see also Department of Health, Response to the Consultation on Draft Regulations and Guidance (n 47) 29; but $c f$ Department of Health, 'Care and Support Statutory Guidance’ (n 9) [9.62]-[9.63].

${ }^{61}$ Department of Health, 'Care and Support Statutory Guidance' (n 9) [9.62]-[9.63].
} 
required to accept a first charge' ${ }^{62}$ The government noted that 'this response was not limited to local authorities, and included providers, the professional services sector, and representative groups and voluntary organisations', and that 'indeed more of the latter category were opposed than were in favour'. ${ }^{63}$ An assumption is clearly being made that any acquisition or other mortgage that already burdened the property will generally have been discharged before a person requires care.

The final guidance makes clear that (as seen above) there will in some circumstances be an obligation to make DPAs available throughout England under the Care and Support (Deferred Payment) Regulations 2014. An adult must be offered a DPA if her needs are to be met in a care home, she has no more than $£ 23,250$ in assets excluding the home and the home is not disregarded. ${ }^{64} \mathrm{~A}$ local authority may nevertheless offer an agreement to someone who does not meet these criteria, and is advised to take into account various matters, including the extent of the adult's accessible assets left after meeting care costs, whether the adult wants to use the home to purchase top-ups to secure more expensive care and whether she misses the mandatory criteria only narrowly. ${ }^{65}$

The guidance states that a local authority may refuse to enter a DPA to someone meeting the above criteria where it is unable to obtain a first charge, the person is seeking a top-up (in which case an appropriate agreement can still be offered) or the adult does not agree to the arrangement's terms and conditions, ${ }^{66}$ although anecdotal evidence suggests that some local authorities are refusing to comply on other grounds. ${ }^{67}$ Where mandatory criteria are unsatisfied, the local authority may and should consider exercising its discretion to offer a DPA.

\footnotetext{
${ }^{62}$ Department of Health, Response to the Consultation on Draft Regulations and Guidance (n 47) 29.

${ }^{63}$ ibid 29.

${ }^{64}$ Department of Health, 'Care and Support Statutory Guidance' (n 9) [9.7].

65 ibid [9.8].

${ }^{66}$ ibid [9.12].

${ }^{67}$ See, eg, O Rudgard, 'Councils "Needlessly” Forcing Elderly to Sell Homes to Pay for Care', Daily Telegraph, 16 February 2016, available at www.telegraph.co.uk/finance/personalfinance/insurance/longtermcare/12140072/Councils-needlessly-forcingelderly-to-sell-homes-to-pay-for-care.html.
} 
A local authority may refuse to defer further costs under an existing agreement (as the amount actually spent on care increases) where the person's assets fall below the threshold or become disregarded such that the person becomes eligible for mean-tested help, the person no longer needs care in a care home or the person has committed a non-resolved breach of the agreement and the agreement permits a refusal to defer further. ${ }^{68}$ Oddly, the situation where the person no longer needs support in a care home appears in both the discretionary and mandatory refusal categories. $^{69}$

The guidance also states that a local authority should not exercise its discretion to refuse further deferrals where the person would be unable to pay any liability that became due as a result from their non-housing assets, ${ }^{70}$ but it must refuse further deferrals where a person has reached their 'equity limit', with such refusal presumably prompting immediate sale (prejudicial to former co-residents) in some cases. This limit on the amount that can be deferred is effectively determined by the amount of equity the person has in the chosen security (usually the home), the amount that the person is contributing towards care costs from non-housing sources, and the total care costs that will be faced (including top-up payments made to secure more expensive accommodation). ${ }^{71}$ The 'equity limit' will also leave some equity available to cover subsequent interest and variations in the value of the security. ${ }^{72}$ It is set at the value of the property minus 10 per cent, minus the lower capital limit for means-tested assistance (currently $£ 14,250$ ) and minus the amount by which the property is already encumbered through security interests ranking in priority to the local authority's charge. ${ }^{73}$

When calculating the amount that a person is able to contribute from other sources, the local authority must enable her to keep (at that person’s option) up to $£ 144$ per week as a 'disposable

\footnotetext{
${ }^{68}$ Department of Health, 'Care and Support Statutory Guidance' (n 9) [9.16].

${ }^{69}$ ibid [9.18].

${ }^{70}$ ibid [9.17].

${ }^{71}$ ibid [9.35].

72 Care and Support (Deferred Payment) Regulations 2014, r 5(5); Department of Health, 'Care and Support Statutory Guidance’ (n 9) [9.36].

${ }^{73}$ Care and Support (Deferred Payment) Regulations 2014, r 5(5); Department of Health, 'Care and Support Statutory Guidance' (n 9) [9.38].
} 
income allowance' ${ }^{74}$ A person should in principle be able to defer all care costs (including topups), but the agreement must be sustainable in an overall sense. ${ }^{75}$

Very significantly for present purposes, the statutory guidance provides that the local authority must also seek consent from anyone with a legal or beneficial interest in the property when proposing to enter a DPA, ${ }^{76}$ which could, of course, include many of the former co-residents with which this chapter is concerned. This alleged obligation is not necessarily consistent with the regulations themselves, however, which state that consent should be obtained from a person 'who the authority considers has an interest in the land or other asset in respect of which a charge will be obtained' and 'whose interest the authority considers may prevent it from exercising a power of sale of the land or asset or recovering the deferred amount', ${ }^{77}$ but only if 'the authority considers it is necessary to do so'. ${ }^{78}$ This leaves much discretion in the hands of the local authority, although it will be in the local authority's interest to obtain consent.

The relevant consent is defined in the regulations as consent that in the opinion of the local authority is genuine and informed consent given in writing, ${ }^{79}$ to 'the creation of a charge'; and 'the charge taking priority to and ranking before any interest the person [consenting] has in the land or other asset which will be the subject of the charge'. ${ }^{80}$ The notion of 'priority' is extremely controversial in a context where the co-resident is in principle not intended to be liable for the care recipient's care in the first place. If the 'priority' is to have any substantive meaning beyond the ability to exercise a power of sale without resorting to the Trusts of Land and Appointment of Trustees Act 1996 (to be discussed in due course), ${ }^{81}$ it presumably means that the co-resident's share can in principle be used to satisfy the debt where the originally assessed amount of the liability is greater than the amount raised by the care recipient's share

\footnotetext{
${ }^{74}$ Department of Health, 'Care and Support Statutory Guidance' (n 9) [9.44].

75 ibid [9.50].

${ }^{76}$ ibid [9.58]-[9.61].

${ }^{77}$ Care and Support (Deferred Payment) Regulations 2014, r 4(4).

78 ibid r 4(1)(b).

${ }^{79}$ ibid r 4(4).

${ }^{80}$ ibid r 4(5).

${ }^{81}$ Trusts of Land and Appointment of Trustees Act 1996, ss 14-15; cf Law of Property Act 1925, s 103.
} 
on sale. The difficulties of valuing and including a care recipient's share where a co-owner also has a beneficial interest must, however, be taken into account.

If a local authority fails to gain consent from a former co-resident, it is presumably at risk of its charge ranking below any beneficial interest of that co-resident (provided that the interest is overriding ${ }^{82}$ and has not been overreached), ${ }^{83}$ and being subject to proceedings under the Trusts of Land and Appointment of Trustees Act 1996 if it wishes to sell the property. This legislation enables a court to consider a wide range of factors when deciding whether to order a sale (including the interests of equitable owners), ${ }^{84}$ albeit that 'the courts tend towards ordering a sale on the general ground that a secured creditor should not be kept out of its money' in such cases (generally involving private creditors). ${ }^{85}$ Since, by definition, the loan advanced under a DPA is not made by virtue of an acquisition mortgage, the principle in Paddington Building Society $v$ Mendelsohn on the implied consent of an equitable co-owner in such circumstances cannot be directly applied. ${ }^{86}$ It may be possible to argue by analogy, however, that the co-resident knew that care was required, that it prima facie had to be paid for and that a charge on the home as part of a DPA was the only means by which this could be achieved without selling the home.

The undue influence doctrine is presumably another means through which a local authority can lose priority to a former co-resident with a beneficial interest, specifically one who has purported to consent to a DPA in the face of pressure from a would-be care recipient who emphasises the lack of realistic alternatives. ${ }^{87}$ The local authority is likely to be put on inquiry in respect of such influence being exerted by a care recipient, since it is unlikely that a care

\footnotetext{
${ }^{82}$ Land Registration Act 2002, s 29; sch 3.

${ }^{83}$ Law of Property Act 1925, s 2.

${ }^{84}$ Trusts of Land and Appointment of Trustees Act 1996, s 15; cf Law of Property Act 1925, s 103, discussed below.

${ }^{85}$ M Dixon, 'To Sell or not to Sell: That is the Question - The Irony of the Trusts of Land and Appointment of Trustees Act 1996' (2011) 70 Cambridge Law Journal 579, 605. See, eg, Bank of Ireland Home Mortgages Ltd v Bell [2001] 2 All ER (Comm) 920 (CA).

${ }^{86}$ (1985) 50 P \& CR 244 (CA).

${ }^{87}$ See, eg, Royal Bank of Scotland Plc v Etridge (No 2) [2001] UKHL 44, [2002] 2 AC 773.
} 
recipient and a co-resident would be considered to be receiving the loan for their joint benefit. ${ }^{88}$ It may be arguable, however, that the co-resident is receiving indirect benefit for the loan, particularly if he is being relieved of informal caring responsibilities through the provision of formal social care. In any event, a would-be care recipient may be more readily considered a potential victim of undue influence rather than a potential perpetrator. ${ }^{89}$

The statutory guidance on the Care Act was amended inter alia to ensure that local authorities 'signpost' people to independent financial advice (including regulated financial advice) where appropriate before taking out a DPA. ${ }^{90}$ The facilitation of access to independent financial advice is included within a local authority's information and advice-related obligations under section 4 of the Act, though there are concerns that the advice-related duty is a general duty that does not seek to ensure that advice is received and understood, ${ }^{91}$ and the focus is likely to be on the care recipient rather than any co-resident.

The regulations set out fairly restrictive provisions about the terms that a DPA must contain. It is not clear what effect a failure to comply with these obligations might have on the validity of the relevant charge, particularly in light of the basic conclusiveness of the land register. ${ }^{92}$ The mandatory terms are described (somewhat generally) as 'any terms, conditions and information, without which the adult is unable to ascertain his or her rights and obligations under the agreement'. ${ }^{93}$ They are expressed to include terms: 'to make clear that the local authority will make advances of [the] loan to the adult in instalments and when those instalments will be made'; ${ }^{94}$ 'to explain that the local authority must cease to defer amounts due ... or advance instalments ... if the adult is no longer receiving care and support in a care

\footnotetext{
${ }^{88}$ CIBC Mortgages Plc v Pitt [1994] 1 AC 200 (HL).

${ }^{89}$ See, eg, Sloan, Informal Carers and Private Law (n 7), ch 7.

${ }^{90}$ Department of Health, Response to the Consultation on Draft Regulations and Guidance (n 47) 28; see also Spencer-Lane (n 38) [1-047]-[1-048], but $c f$ Care and Support (Deferred Payment) Regulations 2014, r 4.

${ }^{91}$ Spencer-Lane (n 38) [1-046].

${ }^{92}$ Land Registration Act 2002, s 58. The 'creation of a protected first legal mortgage' would trigger compulsory first registration of a previously unregistered freehold estate: Land Registration Act 2002, s 4(1)(g).

${ }^{93}$ Care and Support (Deferred Payment) Regulations 2014, r 11(1).

94 ibid r 11(1)(a).
} 
home or [similar] or if the local authority no longer considers that the adult's needs should be met by the provision of such accommodation'; 95 'to explain any other circumstances in which the local authority will or may' cease so to defer or advance, ${ }^{96}$ requiring the local authority every six months (or when requested) to provide a written statement of the amount necessary to terminate the agreement and the accrued administration and interest charges ${ }^{97}$ (in addition to information on the costs that may be charged) $;{ }^{98}$ requiring the local authority to give 30 days' notice of the date that the equity limit (which itself must be explained) ${ }^{99}$ or agreed deferral limit will be reached; ${ }^{100}$ to explain how the interest will compound; ${ }^{101}$ to make clear that where there is genuine loan its purpose 'is to pay the costs of care and support in a care home or supported living accommodation ... and that the adult must pay those costs as and when they fall due'; ${ }^{102}$ describing 'the adequate security accepted by the local authority'; ${ }^{103}$ 'requiring the adult to obtain the consent of the local authority for any person to occupy the property ${ }^{104}$ (which might prejudice the former co-resident, since it does not appear to exclude those who are already occupying the property); and 'to explain how the adult may exercise his or her right to terminate the agreement'. ${ }^{105}$ This suggests that DPAs are heavily regulated, although, again, the focus of protection will inevitably be on the care recipient rather than any co-resident.

\footnotetext{
95 ibid r 11(1)(b).

96 ibid r 11(1)(c).

${ }^{97}$ ibid r 11(1)(d).

98 ibid r 11(1)(g).

99 ibid r 11(1)(i).

${ }^{100}$ ibid r 11(1)(e).

101 ibid r 11(1)(f).

102 ibid r 11(1)(h).

${ }^{103}$ ibid r 11(1)(j).

${ }^{104}$ ibid r 11(1)(k).

105 ibid r 11(1)(1).
} 
In addition, the DPA may 'include such other terms and conditions as the local authority considers appropriate'. ${ }^{106}$ It is interesting that a power of sale is not expressly included amongst the mandatory terms, but in the case of a mortgage created by deed one will presumably be implied under the Law of Property Act $1925,{ }^{107}$ unless 'a contrary intention is ... expressed in the mortgage deed'. ${ }^{108}$ It is clear that such a power is contemplated, moreover, by the explicit reference to one in the description of a person whose consent should be obtained. ${ }^{109}$

The statutory guidance acknowledges that a DPA may be 'regulated credit agreements to which the Consumer Credit Act 1974 ... and Financial Services and Markets Act 2000 (FSMA) apply', ${ }^{110}$ while claiming that '[i]t is likely that most DPAs will fall within ... an exemption'. ${ }^{111}$ It is certainly true that local authorities benefit from a wide range of exemptions relating to 'regulated mortgage contracts' for the purposes of the FSMA. ${ }^{112}$ This reduces the relevance of the Mortgage Conduct of Business Rules (MCOB) themselves to charges possessed by local authorities, ${ }^{113}$ although that should be seen in the context of the regulations governing the content of a DPA, the general statutory provisions applicable, the statutory guidance concerning them and the 'public law' principles relevant to local authorities. ${ }^{114}$ Even second charges taken by local authorities were exempt from the provisions of the Consumer Credit Act $1974 .^{115}$

The local authority's right to possession is not expressly mentioned in the DPA Regulations, but (similarly to the power of sale) in the case of legal mortgages such a right would presumably

\footnotetext{
${ }^{106}$ ibid r 11(2).

${ }^{107}$ Law of Property Act 1925, s 101(1)(i).

108 ibid s 101(4).

${ }^{109}$ Care and Support (Deferred Payment) Regulations 2014, r 4(4).

${ }^{110}$ Department of Health, 'Care and Support Statutory Guidance' (n 9) [9.81].

111 ibid [9.83].

${ }^{112}$ Financial Services and Markets Act 2000 (Regulated Activities) Order SI 2001/544, rr 63A, 72 G.

113 Financial Conduct Authority, 'MCOB Mortgages and Home Finance: Conduct of Business Sourcebook', available at www.handbook.fca.org.uk/handbook/MCOB/ (accessed on 29 November 2016).

${ }^{114}$ See, eg, Department of Health, 'Care and Support Statutory Guidance’ (n 9) Annex D [8].

${ }^{115}$ Consumer Credit Act 1974, s 16(1).
} 
be conferred by the Law of Property Act $1925 .{ }^{116}$ One local authority does indeed warn parties to DPAs that '[i]f you do not make payment when it falls due, legal proceedings may be issued against you for a judgment for the amount you owe and/or for possession of the Property'. ${ }^{117}$ A purported exercise of the right to possession would trigger the Pre-Action Protocol for Possession Claims based on Mortgage or Home Purchase Plan Arrears in Respect of Residential Property (the Protocol) ${ }^{118}$ because it applies even to 'unregulated residential mortgages'. ${ }^{119}$ McFarlane, Hopkins and Nield assert that the Protocol 'reflects MCOB 13', ${ }^{120}$ which is significant in light of MCOB's lack of direct applicability to local authority mortgages. For example, the Protocol specifies a general expectation that the lender will not 'consider starting a possession claim for mortgage arrears' where the borrower has inter alia 'a reasonable expectation, providing evidence where possible, of an improvement in their financial circumstances in the foreseeable future (for example a new job or increased income from a lodger) ${ }^{1}{ }^{121}$ That said, Whitehouse has asserted that 'the potential for the ... Protocol to impact significantly upon the behaviour of lenders prior to court action and, thereby, to assist borrowers in avoiding repossession, is minimal', ${ }^{122}$ and once again the focus appears to be on the borrower herself rather than any co-resident. The process of enforcing the relevant debt and selling the home is considered in more depth in the next section.

\footnotetext{
${ }^{116}$ Law of Property Act 1925, ss 85, 87.

117 Gloucester County Council, 'Deferred Payments Agreement Policy' (2015), available at
} www.gloucestershire.gov.uk/extra/CHttpHandler.ashx?id=35219\&p=0, 27 (accessed on 29 November 2016).

${ }^{118}$ Ministry of Justice, 'Pre-Action Protocol for Possession Claims based on Mortgage or Home Purchase Plan Arrears in Respect of Residential Property' (2015), available at www.justice.gov.uk/courts/procedurerules/civil/protocol/prot_mha (accessed on 29 November 2016).

119 ibid [4.1].

${ }^{120}$ B McFarlane, N Hopkins and S Nield, Land Law: Text, Cases and Materials, 3rd edn (Oxford, Oxford University Press, 2015) 1137.

${ }^{121}$ Ministry of Justice (n 118) [6.1].

${ }^{122}$ L Whitehouse, 'The Mortgage Arrears Pre-Action Protocol: An Opportunity Lost' (2009) 72 Modern Law Review 793, 794. 


\section{Enforcing Debts and Selling Homes}

This section considers the actual recovery of debts under the 2014 Act, addressed by section 69 inter alia, and how this might impact upon the sale of the home still occupied by a former co-resident, whether or not a charge has previously been created as outlined in the previous section. The statutory guidance emphasises that debt recovery is a 'sensitive issue', albeit with particular reference to such recovery from care recipients rather than other people, including former co-residents. ${ }^{123}$ It also states that ' $[\mathrm{c}]$ ourt action should only be considered after all other reasonable avenues have been exhausted', ${ }^{124}$ and contemplates circumstances where it would be inappropriate to recover a debt at all. ${ }^{125}$

One of the generally applicable statutory principles is the new well-being principle. ${ }^{126}$ This provides that ' $[\mathrm{t}]$ he general duty of a local authority, in exercising a function under [Part 1 of the Act] in the case of an individual, is to promote that individual's well-being,, ${ }^{127}$ with 'wellbeing' defined as encompassing several elements ${ }^{128}$ and a number of matters being specified as mandatory relevant considerations. ${ }^{129}$ While the principle is laudable and is not limited in scope to the direct recipients of social care (such that it may include some co-residents), ${ }^{130}$ the government has admitted that it is 'designed to set out the overarching purpose of care and support into which specific duties ... fit, rather than require a local authority to undertake any particular action in ... itself' ${ }^{131}$

\footnotetext{
${ }^{123}$ Department of Health, 'Care and Support Statutory Guidance' (n 9) Annex D [6]. 
In the documentation relating to the Draft Care and Support Bill pre-dating the 2014 Act, it was said that the provisions in what is now section 69 'consolidate various powers, including section 45 of the National Assistance Act 1948, and sections 22-24 of the Health and Social Services and Social Security Adjudications Act 1983', ${ }^{132}$ with section 23 applying to Scotland only. Section 45 covered a person who, 'whether fraudulently or otherwise ... misrepresents or fails to disclose any material fact', 133 causing the local authority to incur expenditure under Part III of that $\mathrm{Act}^{134}$ or not to recover a relevant sum, ${ }^{135}$ and allowed the local authority to recover the amount from the relevant person. Section 22 of the 1983 Act applied only to residential care, and (as we have seen) allowed the local authority to create a charge over land in which a person who 'fails to pay any sum assessed as due to be paid by him for the accommodation ${ }^{136}$ has a beneficial interest. In registered land, that charge was deemed by statute to 'be a registrable charge taking effect as a charge by way of legal mortgage' ${ }^{137}$ Section 24 allowed interest to be applied to the secured sum, but only from the date of the accommodated person's death.

The new debt recovery provisions were reported to be a 'significant area of concern' during the government consultation exercise, because the draft guidance was seen to be too 'light touch'. ${ }^{138}$ Whereas the powers under the Health and Social Services and Social Security Adjudications Act 1983 were 'unilateral' because the opportunity for the local authority to create a charge did not provide the debtor with an alternative means of payment, the guidance goes as far as to claim that section 69 of the 2014 Act 'provides equal protection to both the

\footnotetext{
${ }^{132}$ HM Government, Draft Care and Support Bill (Cm 8386, 2012) 74.

${ }^{133}$ National Assistance Act 1948, s 45(1).

134 ibid s 45(1)(a).

135 ibid s 45(1)(b).

${ }^{136}$ Health and Social Services and Social Security Adjudications Act 1983, s 22(1)(a).

${ }^{137}$ ibid s 22(8).

${ }^{138}$ Department of Health, Response to the Consultation on Draft Regulations and Guidance (n 47) 25.
} 
local authority and the person', ${ }^{139}$ and the Impact Assessment claims that it 'brings current practice up to the legal minimum expected in all other fields of debt recovery'. ${ }^{140}$

Section 69 expressly provides that '[a]ny sum due to a local authority under [Part 1 of the Act] is recoverable by the authority as a debt due to it', ${ }^{141}$ and the cost of (at least attempting) to recover the debt can be added to it. ${ }^{142}$ This is set out without regard to whether the care provided is residential. The local authority is required to offer a DPA where possible ${ }^{143}$ under the relevant DPA regulations, ${ }^{144}$ and can apply to court to enforce a debt only where a DPA is not possible or is refused by the person who owes the debt. This statutory obligation is unlikely to be relevant to the core situation addressed in this chapter, however, since this chapter is primarily concerned with cases where the amount advanced under any DPA has become due for payment (often because the care recipient has died) in any event.

The Care Act has apparently doubled the length of time (from three to six years) in which a debt can be recovered. ${ }^{145}$ Provided that proceedings have been issued within six years, the debt can still be recovered, but otherwise it must be written off. ${ }^{146}$ While there is a specific power for the Secretary of State to make regulations regarding the time a sum is due, when it is not recoverable and the charging of interest, ${ }^{147}$ Halsbury's Annotations claim that no regulations have been made under section $69 .{ }^{148}$

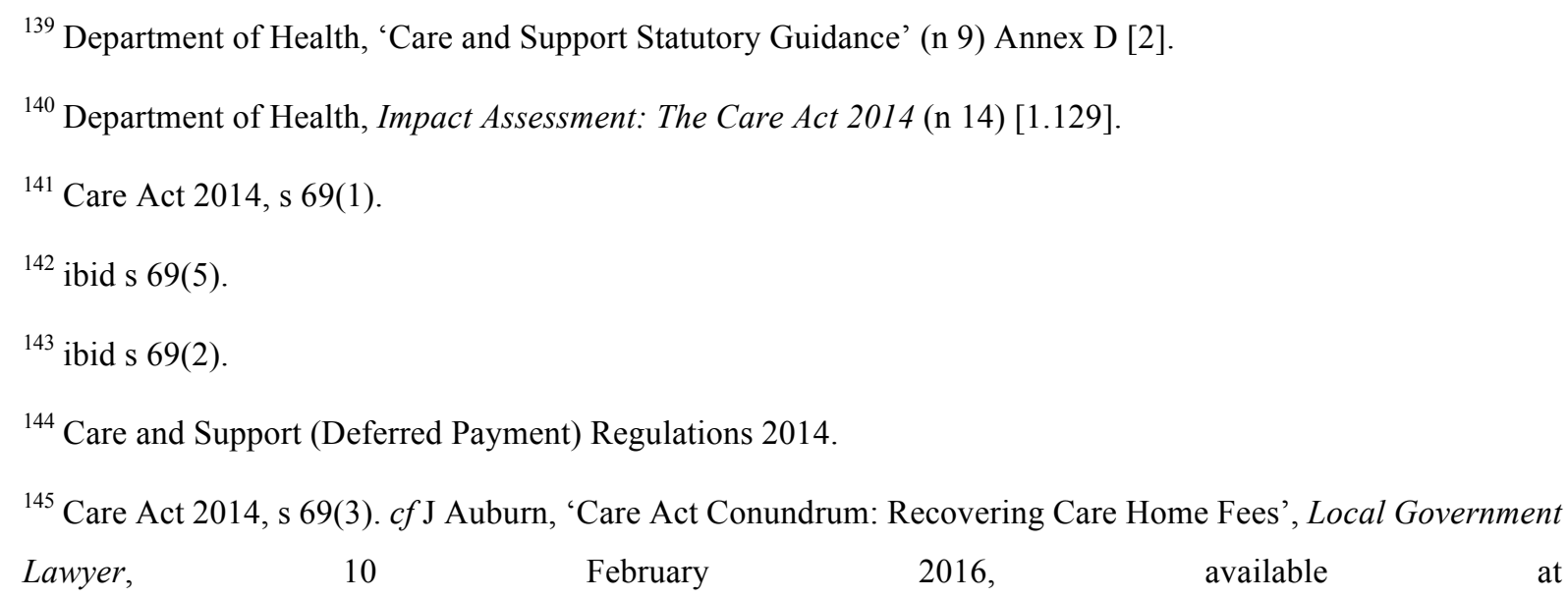
www.localgovernmentlawyer.co.uk/index.php?option $=$ com_content\&view $=$ article\&id=25929\%3Acare-actconundrum-recovering-care-home-fees \&catid=52\&Itemid=20 (accessed on 29 November 2016).

${ }^{146}$ Department of Health, 'Care and Support Statutory Guidance' (n 9) Annex D [11].

${ }^{147}$ Care Act 2014, s 69(6).

${ }^{148 ،}$ 'Care Act 2014, s 69', Halsbury's Annotations (London, LexisNexis, 2016). 
The statutory guidance simply states that if, after the 90-day period following death of a care recipient where a DPA is in place,

a local authority concludes active steps to repay the debt are not being taken, for example if the sale is not progressing and a local authority has actively sought to resolve the situation (or the local authority concludes the executor is wilfully obstructing sale of the property), the local authority may enter into legal proceedings to reclaim the amount due to it

in accordance with the general debt recovery provisions in section 69 of the Act and Annex D of the guidance. ${ }^{149}$

The preference given to a charge by way of legal mortgage presumably means that the statutory provisions usually governing such mortgages will potentially apply to many DPAs. This would include, for example, the restrictions on the exercise of a power of sale if the care recipient were still alive under the Law of Property Act $1925,{ }^{150}$ meaning that some interest under the mortgage must be in arrears and have been unpaid for two months after becoming due, three months must have elapsed since notice requiring payment of the mortgage money was served on at least one mortgagor (which may not be relevant where the care recipient has died) or there must have been some breach of a non-payment covenant by the mortgagor or someone who agreed to the mortgage.

If the care recipient has died (as many will have done by the time a DPA comes to be enforced) and the former co-resident lacked a pre-existing beneficial interest in the property, the home would fairly routinely be sold in the context of the personal representatives' duty to pay the debts of the estate. ${ }^{151}$ This would be true even if the former co-resident is prima facie entitled to inherit the relevant home under a will or the intestacy rules, particularly since it is thought that he would possess only a chose in action to compel due administration of the estate until that administration is complete. ${ }^{152}$ Section 35 of the Administration of Estates Act 1925

\footnotetext{
${ }^{149}$ Department of Health, 'Care and Support Statutory Guidance' (n 9) [9-104].

${ }^{150}$ Law of Property Act 1925, s 103. See, eg, Bury Council, 'Deferred Payments Scheme: Care Act 2014 (Residential Care Funding)'

https://councildecisions.bury.gov.uk/documents/s9222/Deferred\%20Payments\%20Scheme\%20Policy\%20June \%202015.pdf (accessed on 29 November 2016) [11.10].

${ }^{151}$ See generally R Kerridge, Parry and Kerridge: The Law of Succession, 13th edn (London, Sweet \& Maxwell, 2016) $\operatorname{ch} 21$.

${ }^{152}$ Re Leigh's Will Trusts [1970] Ch 277.
} 
imposes a presumption that secured debts should be paid out of the asset over which the security exists where it has been bequeathed by will. The section expressly provides that the rights of the chargee will be unaffected by the presumption, ${ }^{153}$ which means that the local authority would retain a power of sale contained in a DPA. ${ }^{154}$

Such a sale also seems inevitable on death of the care recipient where the former co-resident did have a pre-existing proprietary interest but was bound by the local authority's charge, unless the former co-resident is able to discharge the relevant debt himself and the local authority consents to his doing so. Where the former co-resident has a pre-existing proprietary interest that is not bound by the charge (for the reasons considered in Section III), he could presumably use the Trusts of Land and Appointment of Trustees Act in an attempt to resist the sale. ${ }^{155}$ While the outcome of any such application would probably reflect the trend towards sale, it is worth noting that Mortgage Corporation $v$ Shaire was a case where a litigant successfully remained in the home notwithstanding an application for sale by her deceased's partner's creditor, subject to her ability to pay interest on a loan fashioned out of the creditor's equity. $^{156}$

Section 36 of the Administration of Justice Act 1970 may apply where a local authority seeks an order for possession of the relevant home. The section allows a court to exercise its discretion to adjourn possession proceedings or suspend the execution of judgment for possession when the mortgagor is apparently 'likely to be able within a reasonable period to pay any sums due under the mortgage or to remedy a default'. ${ }^{157}$ The 'mortgagor' is defined to include 'any person deriving title under the original mortgagor or mortgagee', ${ }^{158}$ which, in turn, is likely to include a person with a beneficial interest in the property who was not a party to the

\footnotetext{
${ }^{153}$ Administration of Estates Act 1925, s 35(3).

${ }^{154}$ Parry and Kerridge (n 151) [21-49].

${ }^{155}$ See, eg, Grindal v Hooper [1999] EG 150 (CS).

${ }^{156}$ Mortgage Corporation v Shaire [2001] Ch 743.

${ }^{157}$ Administration of Justice Act 1970, s 36(1).

${ }^{158}$ ibid s 39(1).
} 
original mortgage, ${ }^{159}$ including a spouse or civil partner with relevant home rights. ${ }^{160}$ There may be difficulties over whether it includes a person who lacked an interest before the care recipient died but was the intended inheritor of the property (inevitably subject to the rights of the now-deceased care recipient's creditors), whom we have seen in all likelihood possesses only a chose in action to compel due administration of the estate. ${ }^{161}$ Hopkins and Nield have cogently criticised the lack of protection against creditors available under section 36 for those who lack a proprietary interest in the home, ${ }^{162}$ which may well include some former coresidents as understood in this chapter. That said, on the facts surrounding $R v$ Somerset County Council, ex p Harcombe, ${ }^{163}$ a local authority decided that it would not be reasonable to enforce the charge it possessed under the 1983 Act while the care recipient's son used it as his main residence. Pertinent considerations were said to be the fact that the son had provided care for his mother at home, that he claimed to have an emotional attachment to the relevant house and that he was not in employment. It took the view, however, that further considerations would come into play on the death of the care recipient, not least the entitlement of the care recipient's daughter to a share in her estate.

Whatever the unfortunate circumstances that might arise for former co-residents where a local authority seeks to enforce a debt through the sale of the care recipient's home, the general law means that such a co-resident is unlikely to be in any worse position than in cases involving another form of secured creditor. Moreover, a local authority is in principle likely to be subject to human rights obligations that have been rejected by the High Court in the context of purely private mortgage arrangements. ${ }^{164}$ The Care Act's impact assessment admitted that the previous power unilaterally to create a charge under the 1983 Act (now removed) 'could lead

\footnotetext{
${ }^{159}$ Cheval Bridging Finance Ltd v Bhasin [2008] EWCA Civ 1613.

${ }^{160}$ Family Law Act 1996, s 55(2).

${ }^{161}$ Re Leigh's Will Trusts (n 152).

${ }^{162}$ S Nield and N Hopkins, 'Human Rights and Mortgage Repossession: Beyond Property Law Using Article 8' (2013) 33 Legal Studies 431.

${ }^{163} R$ v Somerset County Council, ex p Harcombe (n 7).

${ }^{164}$ Horsham Properties Group Ltd v Clark [2008] EWHC 2327 (Ch), [2009] 1 WLR 1255.
} 
to successful challenges under Human Rights legislation'. ${ }^{165}$ It must be noted, however, that even where a public body is the proprietor of a charge over a home and seeks to enforce it, it may be difficult for a former co-resident to argue that the interference with his Article 8 right to respect for his home is disproportionate. ${ }^{166}$ Even so, while it may be legally permissible as a matter of general mortgage law for a mortgagee to exercise its power of sale without first obtaining a court order for possession, ${ }^{167}$ this may not be an appropriate action for a local authority to take where it is opposed by a former co-resident.

Where there is no DPA or pre-existing charge on the care recipient's former home, a charging order (governed by the Charging Orders Act 1979) ${ }^{168}$ is likely to be possible in order to enforce the debt owed to a local authority. ${ }^{169}$ In proceedings concerning a charging order, a former coresident may benefit from the fact that a local authority did not initially have a security interest in the care recipient's home. As Dixon notes, however, even in this context 'there remains a steady preference in favour of a sale against the wishes of the innocent co-owner'. ${ }^{170}$

\section{Conclusion}

The law considered in this chapter is a relatively complex mixture of specific social care provisions, general public law principles and the general law of mortgages. In all likelihood, 'former co-residents' of a social care recipient will generally be in a stronger position than former co-residents of other types of debtors when it comes to the sale of the care recipient's former home, even if some of them have made contributions (in principle voluntarily) to the

\footnotetext{
${ }^{165}$ Department of Health, Impact Assessment: The Care Act 2014 (n 14) [1.128].

${ }^{166}$ See, eg, Hounslow LBC v Powell; Birmingham City Council v Frisby [2011] UKSC 8, [2011] 2 AC 186. cf, eg, Nield and Hopkins (n 162).

${ }^{167}$ Horsham Properties Group Ltd v Clark (n 164).

${ }^{168}$ See generally D Capper, H Conway and L Glennon, 'From Obligations to Proprietary Interests: A Critique of the Charging Orders System in England and Wales' in S Bright (ed), Modern Studies in Property Law, Volume 6 (Oxford, Hart Publishing, 2011).

${ }^{169}$ Department of Health, 'Care and Support Statutory Guidance' (n 9) Annex D [43].

${ }^{170}$ Dixon (n 85) 599. See, eg, Pritchard Englefield (A Firm) v Steinberg [2004] EWHC 1908 (Ch), [2005] 1 P \& CR DG2.
} 
care recipient's care costs to increase the available standard of care. They will often benefit from protection before the loan arrangement is even entered through the 'disregard' system (even if they lack an entitlement relating to the home altogether), and the system is designed (subject to issues of 'priority' under a DPA) to ensure that they are not personally liable to pay for the care recipient's care. This is a highly distinctive feature of the regulation of security interests in the social care context, since it means that the former co-resident can be heavily protected while the would-be mortgagor is often able to obtain substantially the same benefit (ie the care) regardless of whether the charge is created.

Moreover, deferred payment agreements are relatively heavily regulated, and the status of the local authority as a public body in principle produces additional and justifiable safeguards, even if a former co-resident may find himself reliant on the benevolent exercise of discretion by a local authority. The removal of the local authority's power unilaterally to create a charge over the home (effectively meaning that only a charging order is likely to produce a security interest where there is no deferred payment agreement) is also welcome.

It may appear unfortunate for former co-residents still to be able to lose their homes, and care recipients relatively routinely to be deprived of their full testamentary freedom, in the manner facilitated even by the reformed social care system. This is particularly true if the cap on care costs is never implemented and the misfortune is ultimately caused by the policy choice to apply a means test for social care. It is noteworthy, moreover, that in an empirical study on public opinion surrounding the intestacy rules, 'participants felt strongly that the family home should always, initially at least, go to the surviving spouse or cohabiting partner or any relative, friend or companion who might be made homeless by any other arrangement'. ${ }^{171}$ As I have argued elsewhere, however, any reduction in the resources going into the care system may prejudice its ability to cater for those who are genuinely unable to make a contribution towards their own care costs. ${ }^{172}$

\footnotetext{
${ }^{171}$ G Morrell, M Barnard and R Legard, 'The Law of Intestate Succession: Exploring Attitudes among Nontraditional Families' (London, NatCen, 2009) 26.

${ }^{172}$ Sloan, 'Adult Social Care and Property Rights' (n 25) 457.
} 